\title{
Osteopontin and the C-terminal peptide of thrombospondin-4 compete for CD44 binding and have opposite effects on CD 133+ cell colony formation
}

\author{
Gulzhakhan Sadvakassova, Monica C Dobocan and Luis F Congote*
}

Address: Endocrine Laboratory, McGill University Health Centre, 687 avenue des pins, ouest, Montreal, Canada H3A 1A1

Email: Gulzhakhan Sadvakassova - gulzhakhan.sadvakassova@mcgill.ca; Monica C Dobocan - monica.dobocan@mail.mcgill.ca; Luis F Congote* - luis.fernando.congote@mcgill.ca

* Corresponding author

Published: 23 October 2009

BMC Research Notes 2009, 2:215 doi:10.1186/1756-0500-2-2/5
Received: 24 April 2009

Accepted: 23 October 2009

This article is available from: http://www.biomedcentral.com/I756-0500/2/2I5

(c) 2009 Congote et al; licensee BioMed Central Ltd.

This is an Open Access article distributed under the terms of the Creative Commons Attribution License (http://creativecommons.org/licenses/by/2.0), which permits unrestricted use, distribution, and reproduction in any medium, provided the original work is properly cited.

\begin{abstract}
Background: $\mathrm{C} 2 \mathrm{I}$, the C-terminal peptide of thrombospondin-4, has growth promoting activity and was discovered as one of several erythropoietin-dependent endothelial proteins. C2I stimulates red cell formation in anemic mice and is a growth factor for CD34+ and CD36+ hematopoietic cells, skin fibroblasts and kidney epithelial cells. RODI has been identified as an intracellular mediator. Nothing is known about the existence of putative $\mathrm{C} 2 \mathrm{I}$ receptors on plasma membranes of target cells.

Findings: We analyzed the nature of $\mathrm{C} 2 \mathrm{I}$-binding proteins in cell lysates of skin fibroblasts using $\mathrm{C} 2 \mathrm{I}$ affinity columns. The membrane receptor CD44 was identified as $\mathrm{C} 2 \mathrm{I}$-binding protein by mass spectrometry. We were unable to demonstrate any direct involvement of CD44 on cell growth or the effect of $\mathrm{C} 2 \mathrm{I}$ on cell proliferation. A soluble form of CD44 was synthesized in insect cells and purified from culture supernatants with a combination of PVDF filtration in the presence of ammonium sulphate and HPLC. Both osteopontin and hyaluronic acid competitively displaced Biotin-C2I binding to CD44. In a colony-forming assay using primitive CDI33+ hematopoietic stem cells from cord blood, osteopontin and $\mathrm{C} 2 \mathrm{I}$ had opposite effects and $\mathrm{C} 2 \mathrm{I}$ reduced the inhibitory action of osteopontin.

Conclusion: CD44 is a C2I-binding membrane protein. We could not demonstrate an involvement of CD44 in the proliferative action of C2I. Nevertheless, based on the antagonism of $\mathrm{C} 2 \mathrm{I}$ and osteopontin in hematopoietic precursors, we speculate that $\mathrm{C} 2 \mathrm{I}$ could indirectly have a major impact on hematopoietic stem cell proliferation, by hindering osteopontin membrane binding at the level of the bone marrow niche.
\end{abstract}

\section{Background}

Erythropoietin (EPO) is the most important cytokine involved in the production of red cells [1]. In endothelial cells, EPO stimulates the synthesis of proteins involved in red cell formation, such as thrombospondins (TSPs) 1 and $4[2,3]$. TSPs are very large extracellular matrix glycoproteins with multiple functions [4]. The biological activity of the C-terminal, amphipathic peptide of TSP-4 (C21) has been described only recently [2] and therefore nothing is known about putative membrane receptors for the 
peptide on the surface of target cells. Our results on the search for potential C21 receptors can be summarized in three points: (1) CD44 was identified as a C21-binding membrane protein in lysates of skin fibroblasts, but we were not able to demonstrate a direct involvement of CD44 in the mitogenic action of C21. (2) Binding studies with a recombinant CD44 indicated that osteopontin (OPN) competed with C21 for CD44 binding, suggesting a possible function of $\mathrm{C} 21$ as OPN antagonist. (3) C21 and OPN had opposite effects on colony formation in cultures of primitive hematopoietic stem cells. Therefore, we speculate that $\mathrm{C} 21$ binding to CD44 could indirectly stimulate hematopoietic stem cell proliferation by preventing the inhibitory action of osteopontin (OPN).

\section{Methods}

Cell cultures of human skin fibroblasts, 293T kidney epithelial cells and Trichoplusia ni insect cells (TN) were done as previously described [5,6]. Cord blood CD133+ precursor cells (Lonza) were cultured in methylcellulose medium (Methocult H4536, Stem Cell Technologies) supplemented with $3 \mathrm{U} / \mathrm{ml}$ EPO in the presence of $1 \mu \mathrm{M}$ C21 [5] or $0.5 \mu \mathrm{g} / \mathrm{ml}$ recombinant human osteopontin (OPN, carrier-free, R\&D Systems). The cells (5000/ml) were plated on 12-well plates (Costar, $0.5 \mathrm{ml} /$ well). The plasmid pENTR containing the cDNA coding for transcript 4 of human CD44, CD44v4 (Ultimate ORF Clone Collection, ID IOH53593, Invitrogen) was modified to introduce a stop codon at the beginning of the extracellular section of the transmembrane domain of CD44 with the "QuikChange ${ }^{\circledast "}$ Site directed mutagenesis kit (Stratagene). The modified cDNA was integrated into the destination vector $\mathrm{pIB} / \mathrm{V} 5$-His-DEST with clonase (Invitrogen Gateway $^{\mathrm{TM}}$ technology) for insect cell production and the complete CD44 sequence was integrated using the same method into the pLenti6/V5-DEST plasmid for lentiviral transduction in $293 \mathrm{~T}$ cells.

C21-affinity chromatography, gel electrophoresis and MS analysis were done as previously described [5].

Soluble CD44 was isolated from three day supernatants of cultures from transfected TN cells cultured in serum-free Excel 405 medium (Sigma). $100 \mathrm{ml}$ of ice-cold medium were mixed with $2 \mathrm{M}$ Tris- $\mathrm{HCl}, \mathrm{pH} 8$ to a final Tris concentration of $0.1 \mathrm{M}$ and stirred for $10 \mathrm{~min}$. The precipitated proteins were separated by centrifugation at $10,000 \times \mathrm{g}$ for 20 min. The supernatant was mixed with $6 \mathrm{~g} \mathrm{SM-2}$ Adsorbent beads (Bio-Rad) and further stirred on ice for $20 \mathrm{~min}$. The beads were trapped with 4 layers of cheese cloth and the remaining medium was mixed with $43 \mathrm{~g}$ ammonium sulfate and stirred for $1 \mathrm{~h}$. The precipitated proteins were eliminated by centrifugation $(20 \mathrm{~min}$, $10,000 \times \mathrm{g})$ and the supernatant was filtered through Durapore PVDF membranes $(0.22 \mu \mathrm{m}$, Cat. SCGVU02RE,
Millipore). The filter was cut in pieces, gently shook on a nutator at $8^{\circ} \mathrm{C}$ for $20 \mathrm{~min}$, first with $5 \mathrm{ml} 0.3 \%(\mathrm{w} / \mathrm{v})$ Zwittergent 3-16 (Calbiochem) and then with $5 \mathrm{ml} \mathrm{1 \%}$ $(\mathrm{v} / \mathrm{v})$ Triflouroacetic acid (TFA). The two extracts were mixed, warmed up to room temperature and applied to a Vydac semi-preparative C4 column $(10 \times 250 \mathrm{~mm}$, Cat 214TP1010, Grace/Vydac). The column was washed with $30 \mathrm{ml} 0.1 \% \mathrm{TFA}$ and the extract components separated with a gradient of acetonitrile [7]. The collected fractions were immediately lyophilized, dissolved in $60 \mu \mathrm{l}$ of the storage buffer [5]. The fractions containing CD44 were identified by applying $2 \mu \mathrm{l}$ on nitrocellulose paper. The dot blots were developed, scanned and measured as previously indicated [8]. We used a monoclonal anti-CD44 antibody recognizing all CD44 isoforms (R\&D Systems). Digestion of CD44 with peptide:N-glycosidase F (PNGase F, New England Biolabs) was done following the instructions of the manufacturer. Binding of biotinylated C21 (Biotin-C21) to CD44 on nitrocellulose membranes was done as previously described for ROD1 [5]. Binding competition studies were done with the same OPN preparation utilized for cell culture as indicated above and with human umbilical cord hyaluronic acid (potassium salt, Calbiochem).

\section{Results and discussion Identification and potential significance of CD44 as a C2 I binding protein}

CD44 is the only C21-binding cell membrane protein identified so far by mass spectrometry using the C21 affinity chromatography described in Methods. The Mascot (Matrix Science) search program indicated a match to CD44E [GenBank:CAA38951]. We found that another C21-binding protein, the nuclear protein ROD1, plays an active role on the mitogenic activity of C21 [5]. Our original hypothesis was that C21 binds first to CD44, is internalized (as has been demonstrated with the CD44 ligand hyalurodan [9]), goes to the nucleus and binds regulatory proteins such as ROD1, resulting in an inhibition of differentiation and/or stimulation of cell proliferation. ROD1 overexpression in skin fibroblasts and 293T cells resulted in an increased basal cell proliferation and in an enhancement of the mitogenic activity of C21 [5]. Insect cells stably transfected with ROD1 grew faster than non transfected or $\beta$-galactosidase-expressing cells (Fig 1). This is not surprising, because human ROD1 is active in lower eukaryotes such as yeast [10]. Although CD44-like, hyaluronic acid-binding proteins have been identified in primitive invertebrates [11], proliferation of stably CD44 transfected insect cells was not significantly different from that observed in $\beta$-galactosidase-transfected cells (Figure 1 ). The same was the case with $293 \mathrm{~T}$ cells transduced with the complete CD44 sequence. We could not see any significant changes in basal- or C21-mediated increase of cell proliferation (results not shown). The problem with over- 


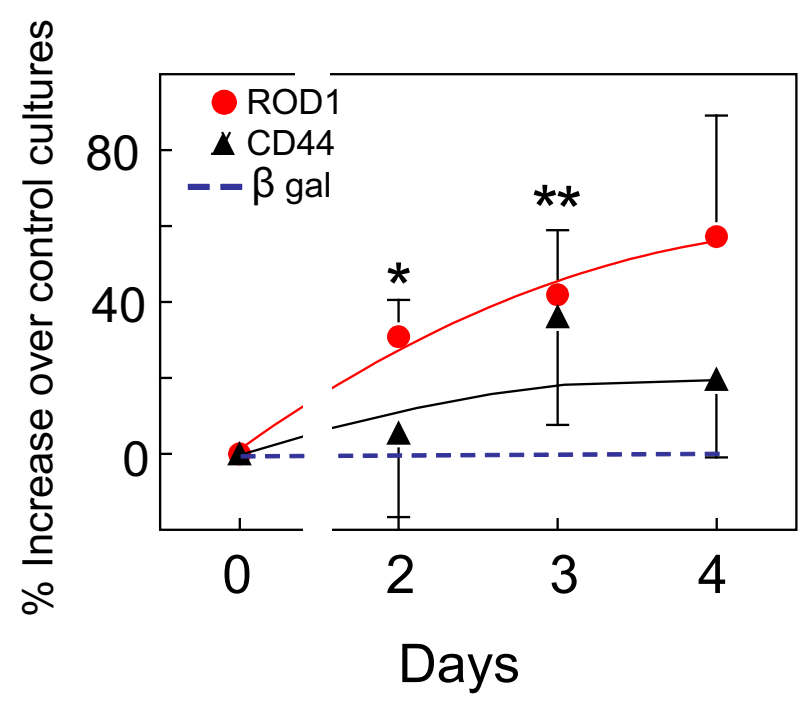

Figure I

Effects of CD44 on insect cell proliferation. TN insect cells were permanently transfected with ROD I [5] or CD44 as indicated in Methods and their growth in culture was compared with parallel control cell cultures transfected with $\beta$ galactosidase. The increase in cell numbers observed in RODI or CD44 transfected cultures was expressed as percentage of the number of cells observed in $\beta$-galactosidase transfected cells after the same day in culture. The values are mean \pm SEM, from 5 to 6 experiments. Only the effects of RODI were statistically different from the controls (KrustalWallis and Dunn's multiple comparisons test). *, $\mathrm{P}<0.05$. **, $\mathrm{P}<0.0$ I.

expression experiments is that negative results are inconclusive. This is particularly valid in the case of CD44. We are overexpressing only one of the many isoforms produced by alternative splicing [12] and a negative result with only one of the transcripts can not exclude the possibility that other CD44 molecules may be active.

\section{Biotin-C2 I binding to CD44 is inhibited by hyaluronic acid and osteopontin}

If CD44 is not implicated in the action of C21, it is still possible that C21-CD44 interactions may have an effect in the function of the membrane receptor in its capacity as a cell-adhesion molecule. The best known ligand of CD44 is hyaluronic acid (HA, hyaluronan), a ubiquitous cell matrix component, which plays an important role in hematopoiesis [13]. Of particular importance is the HA of the endosteal bone marrow niche, which plays a role in primitive hematopoietic stem cell proliferation and homing of transplanted cells to the marrow [14,15]. OPN, another CD44 ligand, is a negative regulatory protein of the hematopoietic stem cell niche $[16,17]$.
Therefore, it was important to investigate the possible interference of C21 with binding to these two CD44 ligands, because it could indirectly play a role in homing and proliferation. For these purpose, we designed a soluble CD44 molecule from a CD44v4 cDNA as indicated in Methods and expressed the recombinant protein using insect cells. The method utilized solved a major technical problem of recombinant protein purification from cell culture supernatants: elimination of xenobiotic components, found in yeast-extract-based serum-free media utilized for protein production with insect or mammalian cells. For the first purification step, we utilized ammonium sulfate precipitation [18]. The human recombinant CD44 produced in insect cells could not be precipitated with ammonium sulfate. Nevertheless, we found that if a CD44 solution is filtered through PVDF membranes in the presence of ammonium sulfate, there is complete retention on the membranes (Figure 2A). This was not observed in the absence of ammonium sulfate. Retention without precipitation could be attributed to a Hofmeister ion effect $[19,20]$ Figure 2B shows the importance of the utilization of PVDF for the retention of CD44. If supernatants are desalted by ultrafiltration, the vast majority of the culture contaminants are retained and CD44 recovery is low (Figure 2B). However, if PVDF retained material is solubilized and applied to HPLC columns, the vast majority of the contaminants of Figure $2 \mathrm{~B}$ is eliminated and the recovery of $\mathrm{CD} 44$ is high (Fig 2C). MS analysis of the protein indicated that it corresponded to human CD44R1, [GenBank:CAA40133], a hematopoietic cell isoform of CD44 [21]. Treatment with a recombinant glycosidase indicated that the protein was extensively $\mathrm{N}$-glycosylated by insect cells (Figure 2C).

This protein was utilized to study the possible competition of biotin-C21 binding to CD44 by HA (Figure 3A) and OPN (Figure 3B). Both $\mathrm{HA}$ and OPN displaced Biotin-C21 binding to CD44. Surprisingly, the inhibition of Biotin-C21 binding caused by increasing amounts of C21 and OPN was practically identical (Figure 3B), suggesting common binding sites for the TSP-4 peptide and OPN. A similar comparison of C21 with HA was not possible, due to the undefined, heterogeneous molecular weight of the HA preparation.

\section{Opposite effects of $\mathrm{C2} I$ and OPN on colony formation of CDI33+ cord blood cells}

The most important function of OPN in hematopoiesis seems to be the suppression of proliferation of primitive stem cells in the bone marrow niche, as evidenced with OPN-/- mice and in vitro colony formation assays [16,17]. The effect of OPN depends on the differentiation state of the stem cells. The inhibitory action is eliminated with the appearance of the cell marker CD38+ [17] and in highly differentiated, primary erythroblasts, OPN actually stimu- 

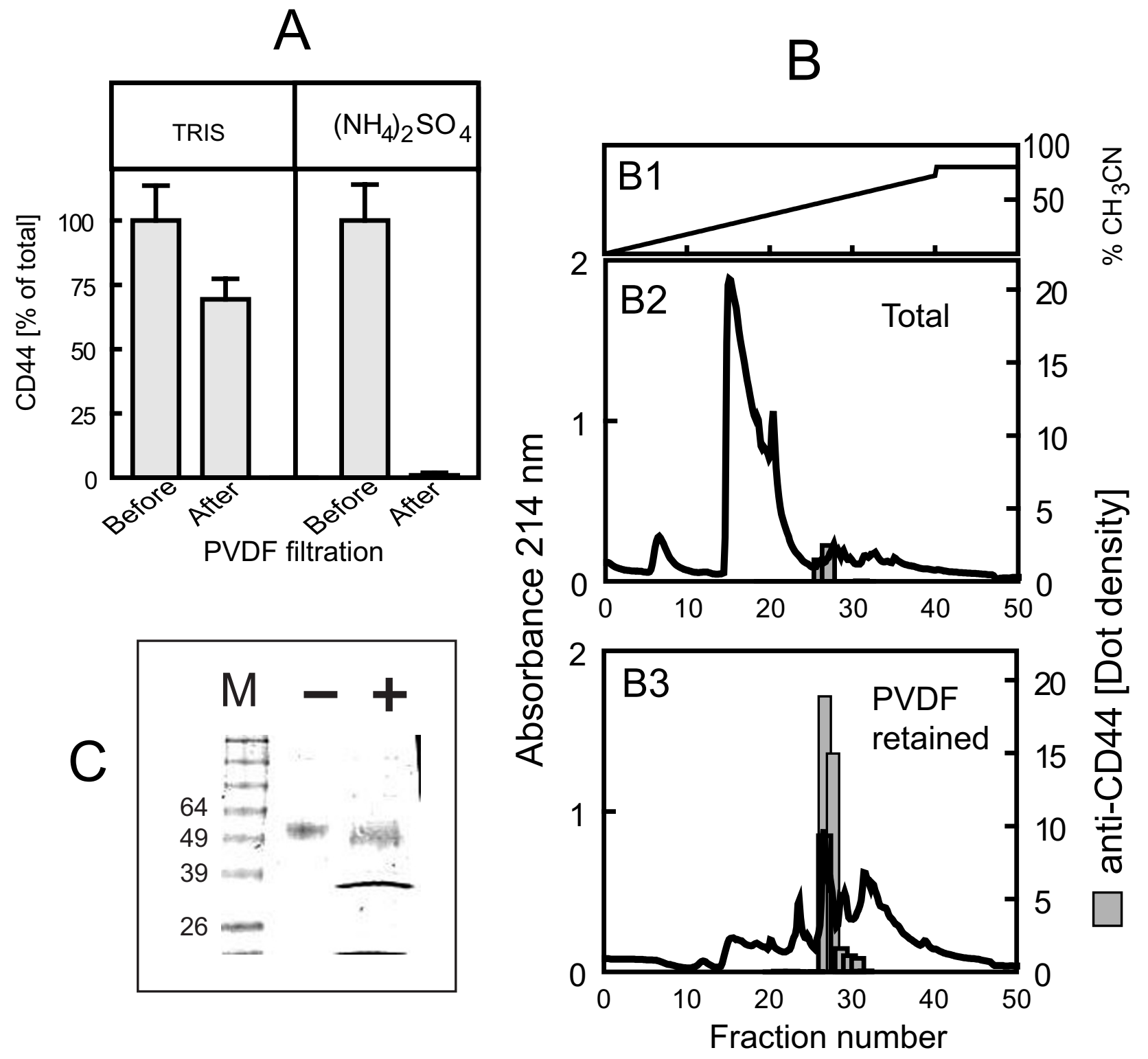

\section{Figure 2}

Preparation of a soluble form of CD44 from insect cell culture medium. (A) Ammonium sulfate is responsible for retention of soluble CD44 on PVDF filters. $22 \mu \mathrm{g}$ CD44 prepared as indicated in Methods were dissolved in $0.3 \mathrm{ml} 0 . \mathrm{I} \mathrm{M}$ Tris$\mathrm{HCl}, \mathrm{pH} 8$ and filtered through Millex-GV low protein binding Durapore, $0.22 \mu \mathrm{m}$ pore size (Millipore SLGV033RS) in Tris buffer alone or with $3 \mathrm{M}$ ammonium sulfate. The ultrafiltrates of ammonium-sulfate containing solutions were practically free of immunoreactive CD44, measured as indicated in Methods. Values are mean \pm SEM $(n=4)$. (B) Reverse phase HPLC of the soluble ammonium sulfate fraction of cell culture supernatants. The supernatants of TN cultures expressing CD44 were processed as indicated in Methods and applied to a Vydac C4 semi-preparative column. (BI) Acetonitrile gradient, $0 \%$ to $72 \%$ ( $/ \mathrm{v}$ ) acetonitrile in $0.1 \%(\mathrm{v} / \mathrm{v})$ TFA for $50 \mathrm{~min}, 2 \mathrm{ml} / \mathrm{min}$. (B2) After centrifugation of the proteins precipitated with ammonium sulfate, the supernatant was desalted and concentrated by ultrafiltration (Centricon-20, cut-off $10 \mathrm{kDa}$, Millipore) and applied to the column. (B3) Instead of ultrafiltration, the supernatant was filtered through PVDF membranes (type GV, $0.22 \mu \mathrm{m})$. The proteins on the filter were extracted and applied to the column. The gray bars represent the density of the immunoreactive fractions using an anti-CD44 antibody. (C) PNGase digestion of recombinant soluble CD44. I20 ng CD44 were applied onto PAGE-SDS gels (I0\% acrylamide) and separated by electrophoresis before $(-)$ and after $(+)$ I h digestion with PNGase F. M = molecular weight markers. The gels were stained with coomassie blue. 


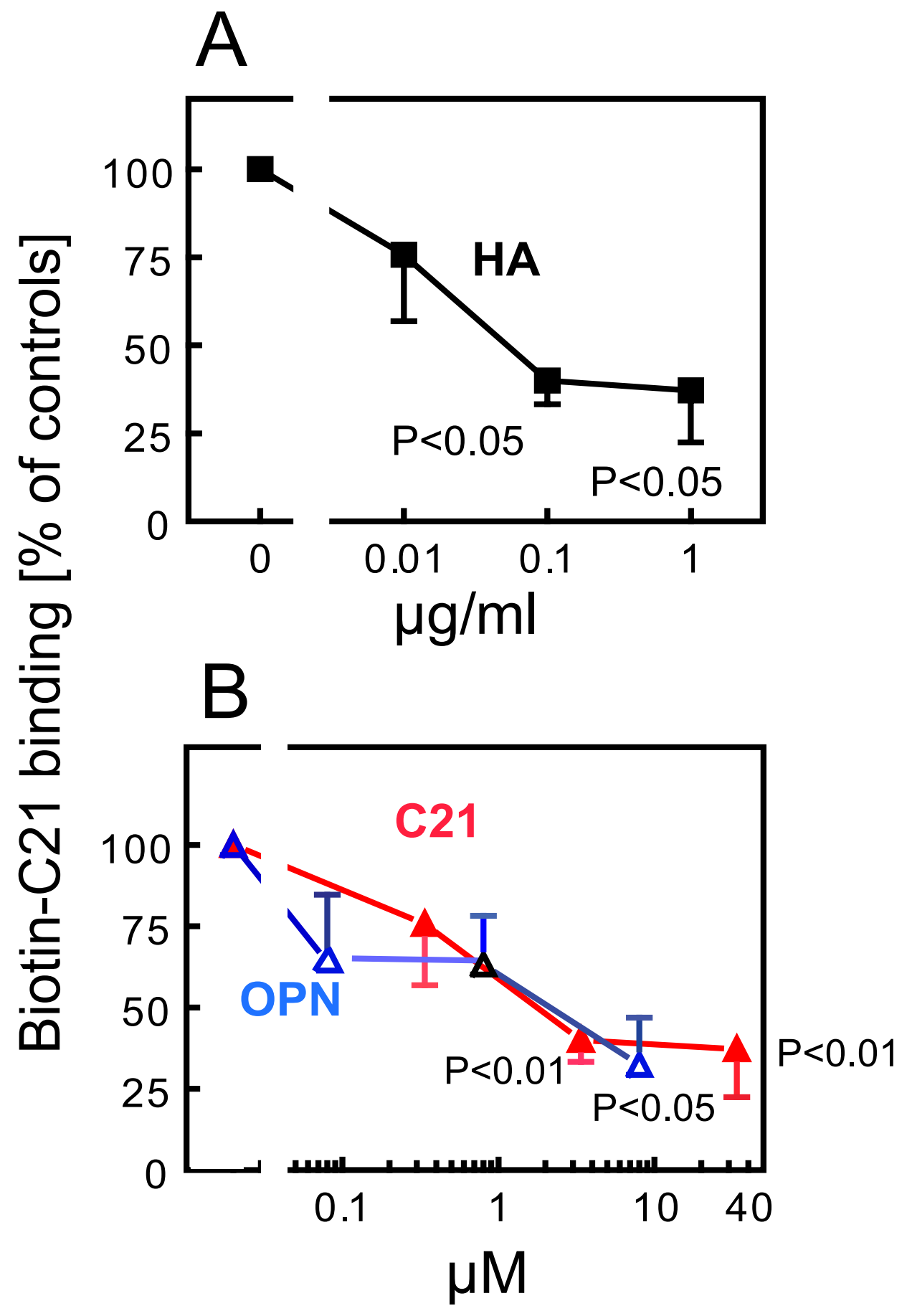

Figure 3

HA and OPN compete for Biotin-C2 I binding to CD44. (A) Binding of Biotin-C2I to CD44 immobilized on nitrocellulose membranes was displaced with increasing concentrations of HA. No displacement is considered as $100 \%$ (controls). Mean \pm SEM. $n=7$. (B) Competition for Biotin-C2I binding to CD44 with increasing concentrations of C2I (closed triangles) or OPN (open triangles). Mean \pm SEM. $n=5$ for $8 \mu$ M OPN, $n=6$ for $0.08 \mu M$ OPN and $0.33 \mu M$ C2I, $n=8$ for $0.8 \mu M$ OPN, $n$ $=9$ for 3.3 and $33 \mu \mathrm{M} \mathrm{C2I}$. P values calculated by analysis of variance and Student-Newman-Keuls test (C2I and HA) or Krustal-Wallis and Dunn's multiple comparisons test (OPN). 
lates cell proliferation [22]. TSP-1 has a similar differentiation-dependent effect on cell proliferation $[3,5]$. The existence of opposite effects of OPN in primitive precursors and differentiated cells is just one example of the more generalized duality of OPN action. This is illustrated by its double action as pro-inflammatory or anti-inflamatory cytokine, observed under normal or pathological conditions, as recently reviewed by Wang and Denhardt [23]. This multiplicity of biological activities, receptors and signal transduction pathways requires a careful choice in the nature and differentiation stage of the target cells to be used in the experiments. OPN-dependent inhibition by $\mathrm{C} 21$ has to be studied in very primitive, CD38- stem cell precursors. We chose CD133+ cells, which can differentiate into hematopoietic or endothelial cells [24,25]. For the experiments on colony formation, we used a minimal serum-free cell culture system without Flt3 ligand, thrombopoietin, VEGF or stromal cell monolayers, usually required for full differentiation into granulocyte-macrophage colonies, erythroid colonies or endothelial cells. Therefore, the colonies formed were compact and small (Figure 4A). Figure 4B shows that $\mathrm{C} 21$ and OPN had opposite effects on colony formation. This antagonistic action was significant. Although the OPN-mediated reduction of colony formation was not significantly different from that observed in control cell cultures in CD133+ cells, probably due to the low number of experiments, the inhibitory action of OPN in similar, primitive hematopoietic stem cells cultures is well established $[16,17]$. There is a correlation between the antagonistic effects of OPN and C21 on colony formation in vitro (Figure 4) with the observed molecular competition for CD44 binding in silico (Figure 3). The contribution of CD44 to this antagonism may be limited, because C21 could stimulate proliferation by CD44-independent pathways and OPN action on colony formation seems to be mediated by $\beta 1$ integrins rather than CD44 [17]. A CD44 involvement is nevertheless quite possible. CD44 binding could passively increase the local, membrane bound concentration of OPN. The most probable scenario is that CD44 actively participates as a coreceptor, bound in lipid rafts to integrin chains. This association leads to integrin activation, as demonstrated in adenocarcinoma cell lines [26].

In conclusion, $\mathrm{C} 21$ could act on target cells by multiple mechanisms, which may involve competition with OPN for CD44 binding sites, ROD1-dependent signal transduction pathways involving proliferation and, probably, ROD1- independent effects on apoptosis, as previously discussed in [5].

\section{Competing interests}

The authors declare that they have no competing interests.
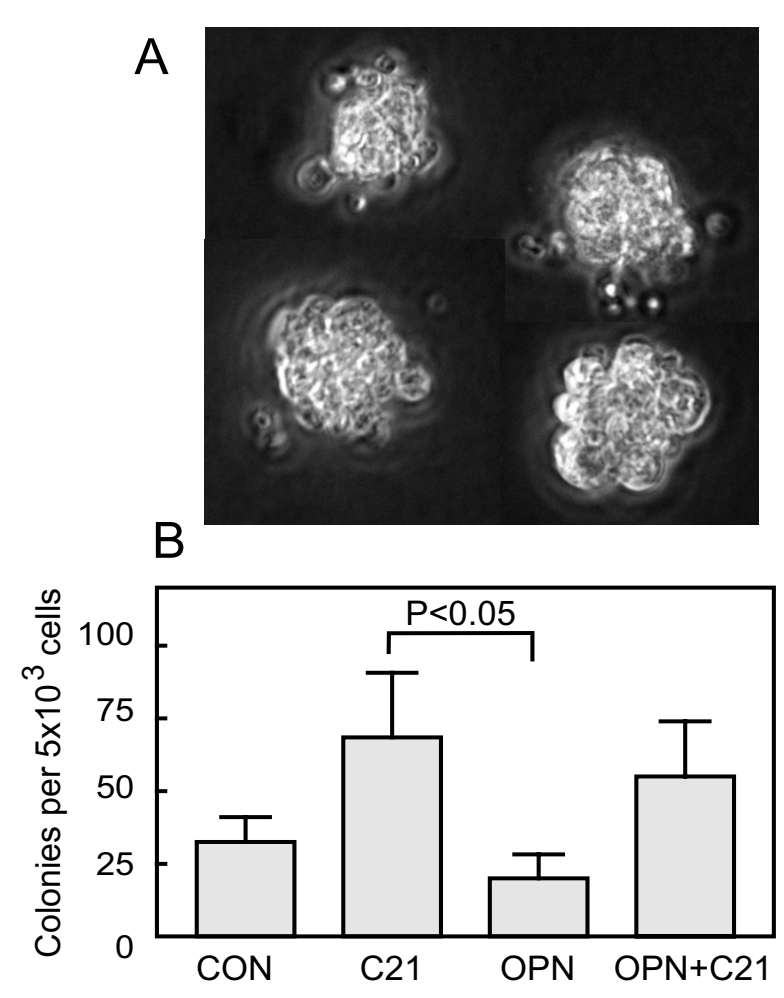

Figure 4

Colony formation of CDI33+ cord blood cells in the presence of C2I and OPN. (A) Microscope images of 4 typical colonies formed after 18 days in culture of CDI33+ cells in the semisolid serum-free medium described in Methods. The "Methocult"-medium contained stem cell factor, GM-CSF, G-CSF, IL-3, IL-6 and EPO. The culture was not done on stromal cell monolayers and did not contain Flt3 ligand, thrombopoietin or VEGF. (B) Total colony cell count observed after 18 days incubation with C2I, OPN or $C 2 I+O P N$. Mean \pm SEM. $n=4$. $P$ value according to Friedman Test (nonparametric repeated measures analysis of variance) and Dunn's multiple comparisons test.

\section{Authors' contributions}

GS performed the experiments on affinity chromatography. GS and MCD did all experiments on plasmid construction, transduction, transfection, cell culture, binding studies and isolation of CD44. LFC wrote the original draft of the manuscript, performed the colony assays and participated in the purification of CD44. All authors read and approved the manuscript.

\section{Acknowledgements}

We thank Drs. Leonid Kriazhev and Marcos Di Falco from the McGill University and Genome Quebec Innovation Centre for in-gel digestion and MS analysis. This work was supported by the Canadian Blood Services/CIHR blood utilization and conservation initiative. 


\section{References}

I. Jelkmann W: Molecular biology of erythropoietin. Intern Med 2004, 43:649-59.

2. Congote LF, Difalco MR, Gibbs BF: The C-terminal peptide of thrombospondin-4 stimulates erythroid cell proliferation. Biochem Biophys Res Commun 2004, 324:673-678.

3. Congote LF, Difalco MR, Gibbs BF: Thrombospondin I, produced by endothelial cells under the action of erythropoietin, stimulates thymidine incorporation into erythroid cells and counteracts the inhibitory action of insulin-like growth factor binding protein 3. Cytokine 2005, 30:248-253.

4. Adams JC, Lawler J: The thrombospondins. Int J Biochem Cell Biol 2004, 36:961-968.

5. Sadvakassova G, Dobocan M, DiFalco MR, Congote LF: Regulator of Differentiation I (RODI) binds to the amphipathic C-terminal peptide of thrombospondin-4 and is involved in its mitogenic activity. J Cell Physiol 2009, 220:672-679.

6. Dobocan M, Sadvakassova G, Congote LF: Chaperonin 10 as an endothelial-derived differentiation factor: role of glycogen synthase kinase-3. J Cell Physiol 2009, 2 I 9:470-476.

7. DiFalco MR, Congote LF: Preparation of a recombinant chimera of insulin-like growth factor II and interleukin 3 with high proliferative potency for hematopoietic cells. Biochem J 1997, 326:407-413.

8. DiFalco MR, Ali S, Congote LF: The improved survival of hematopoietic cells cultured with a fusion protein of insulin-like growth factor II and interleukin 3 is associated with increases in $\mathrm{Bcl}-\mathrm{xL}$ and phosphatidylinositol 3 kinase activity. J Leukocyte Biol 2003, 73:297-305.

9. Culty $M$, Nguyen $H A$, Underhill $C B$ : The hyaluronan receptor (CD44) participates in the uptake and degradation of hyaluronan. J Cell Biol 1992, I I 6: I 055-1062.

10. Yamamoto H, Tsukahara K, Kanaoka $Y$, Jinno S, Okayama H: Isolation of a mammalian homologue of a fission yeast differentiation regulator. Mol Cell Biol 1999, I9:3829-384I.

II. Cabrera PV, Blanco G, Ernst G, Alvarez E, Cooper EL, Hajos S: Coelomocyte locomotion in the sipunculan Themiste petricola induced by exogenous and endogenous chemoattractants: role of a CD44-like antigen-HA interaction. J Invertebr Pathol 2002, 79: I II-I|9.

12. Ponta $H$, Sherman L, Herrlich PA: CD44: from adhesion molecules to signalling regulators. Nat Rev Mol Cell Biol 2003, 4:33-45.

13. Haylock DN, Nilsson SK: The Role of Hyaluronic Acid in Hemopoietic Stem Cell Biology. Regenerative Med 2006, I:437-445.

14. Nilsson SK, Haylock DN, Johnston HM, Occhiodoro T, Brown TJ, Simmons PJ: Hyaluronan is synthesized by primitive hemopoietic cells, participates in their lodgment at the endosteum following transplantation, and is involved in the regulation of their proliferation and differentiation in vitro. Blood 2003 I 0 I:856-862.

15. Avigdor A, Goichberg P, Shivtiel S, Dar A, Peled A, Samira S, Kollet O, Hershkoviz R, Alon R, Hardan I, Ben-Hur H, Naor D, Nagler A, Lapidot T: CD44 and hyaluronic acid cooperate with SDF-I in the trafficking of human CD34+ stem/progenitor cells to the bone marrow. Blood 2004, I 03:298I-2989.

16. Stier S, Ko Y, Forkert R, Lutz C, Neuhaus T, Grunewald E, Cheng T, Dombkowski D, Calvi LM, Rittling SR, Scadden DT: Osteopontin is a hematopoietic stem cell niche component that negatively regulates stem cell pool size. J Exp Med 2005, 20 I: I 78I-I79I.

17. Nilsson SK, Johnston HM, Whitty GA, Williams B, Webb RJ, Denhardt DT, Bertoncello I, Bendall LJ, Simmons PJ, Haylock DN: Osteopontin, a key component of the hematopoietic stem cell niche and regulator of primitive hematopoietic progenitor cells. Blood 2005, 106:1232-1239.

18. Yang H, Binns RM: Isolation and characterization of the soluble and membrane-bound porcine CD44 molecules. Immunology 1993, 78:547-554.

19. Baldwin RL: How Hofmeister ion interactions affect protein stability. Biophys J 1996, 7 I:2056-2063.

20. Leberman R, Soper AK: Effect of high salt concentrations on water structure. Nature 1995, 378:364-366.

21. Dougherty GJ, Landorp PM, Cooper DL, Humphries RK: Molecular cloning of CD44RI and CD44R2, two novel isoforms of the human CD44 lymphocyte "homing" receptor expressed by hemopoietic cells. J Exp Med I99|, I74:|-5.
22. Kang JA, Zhou Y, Weis TL, Liu H, Ulaszek J, Satgurunathan N, Zhou L, van Besien K, Crispino J, Verma A, Low PS, Wickrema A: Osteopontin regulates actin cytoskeleton and contributes to cell proliferation in primary erythroblasts. I Biol Chem 2008 , 283:6997-7006

23. Wang KX, Denhardt DT: Osteopontin: Role in Immune Regulation and Stress Responses. Cytokine Growth Factor Rev 2008 19:333-345.

24. Kawano $Y$, Kobune M, Chiba H, Nakamura K, Takimoto R, Takada K, Ito $Y$, Kato J, Hamada H, Niitsu Y: Ex vivo expansion of G-CSF. mobilized peripheral blood CDI33+ progenitor cells on coculture with human stromal cells. Exp Hematol 2006, 34: I 50- I 58.

25. Bonanno G, Mariotti A, Procoli A, Corallo M, Rutella S, Pessina G, Scambia G, Mancuso S, Pierelli L: Human cord blood CDI33+ cells immunoselected by a clinical-grade apparatus differentiate in vitro into endothelial- and cardiomyocyte-like cells. Transfusion 2007, 47:280-289.

26. Lee JL, Wang MJ, Sudhir PR, Chen JY: CD44 engagement promotes matrix-derived survival through the CD44-SRCintegrin axis in lipid rafts. Mol Cell Biol 2008, 28:57l 0-5723.
Publish with Biomed Central and every scientist can read your work free of charge

"BioMed Central will be the most significant development for disseminating the results of biomedical research in our lifetime. "

Sir Paul Nurse, Cancer Research UK

Your research papers will be:

- available free of charge to the entire biomedical community

- peer reviewed and published immediately upon acceptance

- cited in PubMed and archived on PubMed Central

- yours - you keep the copyright 